\title{
Management Strategies to Harness Cultural Diversity on Australian Construction Sites - a Social Identity Perspective
}

\author{
Martin Loosemore, (University of New South Wales, Australia) \\ Florence Phua, (University of Reading, UK) \\ Melissa Teo, (Queensland University of Technology, Australia) \\ Kevin M. Dunn, (University of Western Sydney, Australia)
}

\begin{abstract}
Construction sites around the world employ large numbers of people from diverse cultural backgrounds. The effective management of this cultural diversity has important implications for the productivity, safety, health and welfare of construction workers and for the performance and reputation of firms which employ them. The findings of a three year, multistaged study of cultural diversity management practices on construction sites are critiqued using social identity theory. This reveals that so called "best-practice" diversity management strategies may have an opposite effect to that intended. It is concluded that the management of diversity on construction projects would benefit from being informed by social identity research.
\end{abstract}

Keywords: Cultural diversity, Racism, Discrimination, Social identity theory.

\section{Introduction}

Major construction projects in most countries employ large numbers of ethnic minorities (Ofori 1994; Hay 1996, Loosemore and Lee 2003, Gale and Davidson 2006, Dainty et al 2007). For example, in Australia, Loosemore et al's (2008) survey of 1150 site operatives found that $57 \%$ spoke a language other than English at home, 54\% had been born in another country and $70 \%$ of parents had been born in another country. Loosemore and Lee's (2003) analysis of Australian construction sites found that large construction sites segregate into ethnically-based occupational groups and cultural ghettos characterised by language and cultural barriers which exclude outsiders (especially those from different ethnic groups). According to Loosemore and Andonakis (2006) and Loosemore et al (2010), these divisions present project managers with a complex dynamic of linguistic and cultural interfaces - some posing more challenges than others - which can affect performance in areas such as productivity, waste, quality and safety. Certain groups are more likely to be seen as problematic by others and that intolerance towards them was more likely to be expressed by those who did not speak a language other than English. In contrast, multilingual speakers were more likely to be tolerant towards other groups. Furthermore, cultural differences and stereotypes play a major role in shaping workers' perceptions of other groups. For example, there is a widespread belief among workers that AustralianLebanese have a different work culture reflected in their aggressive behaviours. In contrast, intolerance towards Asian-Australians mostly occurs on the grounds that Asian-Australians are perceived to dramatically reduce safety standards, wages and professional quality on site. Other research by Dunn et al (2009) indicate that these intergroup attitudes and perceptions might be associated with and influenced by tensions between the two groups within broader society, where similar attitudes are often expressed.

These types of attributes and challenges make the construction industry an especially important setting to study the management of cultural diversity. While other industries such as apparel, pharmaceuticals, entertainment media, information technology, retailing and fast moving consumer goods manage diversity as an asset to improve productivity, innovation and profitability (Cox and Blake 1991, De Cieri and Kramar 2003), management strategies 
used in the construction industry apparently fail to harness its productive potential and this appears to be a common characteristic of the industry globally (Steele and Sodhi 2006, Dainty et al 2007). Within this context, the aim of this paper is to explore and critique current strategies used in the industry to manage cultural diversity and to critique, using social identity theory, the strategies employed by what are perceived to be "best practice" firms in other industries.

\section{A Social Identity Perspective on the Management of Diversity}

As Loosemore et al (2003) and Dainty et al (2007) point out, the construction sector represents one of the most complex and problematic arenas within which to manage people. The challenges inherent in managing a highly diverse workforce distributed across temporary coalitions of loosely coupled firms are significant. And these challenges are exacerbated by the operational realities faced by construction organizations which mean that all too often the needs of those who work for construction firms are subjugated by performance concerns. According to Dainty et al (2007:4) this approach to human resource management reflects rationalist management paradigms which are "strangely disconnected' from theoretical developments in other disciplines". Such approaches underplay the importance of people as a key resource and have likely ingrained many negative assumptions into operational and management practices relating to the value of diversity in the construction sector. Social identity theory offers a new and potentially powerful paradigm to better understand these issues and reframe management practices. This theory offers a theoretical framework for understanding the cognitive mechanisms by which corporative intergroup relations are presumed to work. In doing so it has laid the conceptual foundations for understanding the factors and conditions that encourage in-group favouritism and outgroup discrimination to occur. Social identity theory rests of two basic premises. The first premise is that people understand the social world through categorisation of continuous social variables into discrete classes which has the effect of minimising perceived differences but accentuating inter-category differences (Tajfel 1970). The second premise is that this social categorisation carries with it implicit in-group and out-group (us and them) distinctions. Van Oudenhoven et al (1996) point out in their investigation of interethnic attitude formation, in order to engage member identification and loyalty, groups must develop clear rules for inclusion and exclusion which in turn gives rise to "clique selfishness", ethnocentrism and other forms of in-group ethnic bias which encourage we-they distinctions and further demark boundaries of loyalty and cooperation between ethnic groups. In turn, the attitudes and values of group members become shaped by these in-group and out-group distinctions in that people from other groups are viewed as inferior from an in-group perspective. The obvious conclusion from this theory was that one should eliminate difference, or at least play it down, and pursue the "melting pot" assimilationist approach to diversity management. However, as Brewer (1997) points out, while this would seem to a well founded strategy, implementation of this disaggregation approach in real world settings has proved less than successful and has met with deep resistance to attempts at interethnic assimilation, integration and mergers. Consequently, many social psychologists reconceptualised the importance of in-group differentiation and identification to social relations and advocated an alternative "pluralistic" model for managing inter group relations which recognises the importance of difference (Brewer 2009). This approach argues that distinctive group identities can be complementary and mutually respected leading to positive interdependencies and attributes which can be capitalised on through effective management. These pluralistic notions of "positive distinctiveness" underpin what is now widely known as multiculturalism. However, notions of multiculturalism have also been problematic when it has been used to preserve unequal structures in societies by legally locking-in differential group access to power and resources. The creation of privileged group status has the effect of encouraging monolithic perceptions of cultural groups, reducing opportunities for inequalities to be eliminated and for a common identity to arise (conditions which have long been associated with reduced discrimination in society). In this way, differences become institutionalised. The fact that both assimilationist and multicultural

Loosemore, $\mathrm{M}$ et al. (2012) 'Management strategies to harness cultural diversity on Australian construction sites - a social identity perspective', Australasian Journal of Construction Economics and Building, 12 (1) 1-11 
strategies appear to be equally problematic poses a dilemma for managers who have to operate in a multicultural setting. The answer according to Brewer (1997) is to capitalise more effectively on people's capacity for multiple social identities. In other words, people are capable of being members of and contributing to more than one social group and these cross-cutting identities are the secret to reducing the social comparisons and stereotypes that motivate intercultural conflict. Brewer's research shows that most people have a multicultural heritage and are capable of juggling multiple identities over their lifetime. This approach has very different implications for the development of cultural diversity management strategies in the construction industry. For example, it would question the common practice of making all signage and documentation available in many languages and promote the alternative idea of encouraging bilingualism by teaching everyone to speak two languages (at least in the restricted vocabulary needed to work safety on site etc). The first strategy reinforces difference and teaches people to think of each other as members of distinct groups whereas the second strategy eliminates difference and encourages "collective multiculturalism" as a shared value.

\section{Method}

Using the above ideas, a three-staged method was employed to explore the attitudes that underpin cultural diversity in the Australian construction industry, the management challenges that these pose and the range of strategies that can be employed to manage them more effectively.

\begin{tabular}{|c|c|c|}
\hline \multirow[t]{2}{*}{ Gender } & Male & 100 \\
\hline & Female & 0 \\
\hline \multirow[t]{5}{*}{ Age } & under 18 & 1 \\
\hline & $18-34$ & 42 \\
\hline & $35-54$ & 47 \\
\hline & $55-64$ & 10 \\
\hline & 65 \& over & 1 \\
\hline \multirow[t]{5}{*}{ Education } & No schooling & 2 \\
\hline & Primary & 7 \\
\hline & Secondary & 83 \\
\hline & Bachelors degree & 8 \\
\hline & Postgraduate & 1 \\
\hline \multirow[t]{3}{*}{ Birthplace } & Australia & 47 \\
\hline & $\begin{array}{l}\text { Non-English speaking } \\
\text { countries }\end{array}$ & 40 \\
\hline & English speaking countries & 13 \\
\hline \multirow{2}{*}{$\begin{array}{l}\text { Language } \\
\text { other than English }\end{array}$} & Yes & 57 \\
\hline & No & 43 \\
\hline \multirow[t]{5}{*}{ Religion } & Christian & 71 \\
\hline & no religion & 15 \\
\hline & Islam & 6 \\
\hline & All other beliefs & 3 \\
\hline & inadequately described & 5 \\
\hline
\end{tabular}

Table 1 Respondent demographics, Operatives' survey, Sydney construction sites, 2008

Loosemore, $\mathrm{M}$ et al. (2012) 'Management strategies to harness cultural diversity on Australian construction sites - a social identity perspective', Australasian Journal of Construction Economics and Building, 12 (1) 1-11 
In stage one, we undertook a survey of operatives to identify attitudes about cultural diversity and towards other cultural groups; the positive and negative functions of cultural groupings; the impact of discrimination and racism on constructing inter-communal relations and work practices; and finally existing policies and strategies in dealing with cultural diversity on Australian construction sites. The survey was administered on twenty-nine construction sites in the Sydney metropolitan area. The sites were chosen as typically representative of large construction sites with culturally diverse workforces and most of the questions were closedended in yes-no format since many operatives were from a lower educational background and had poor English language skills (particularly Chinese and Koreans). Where necessary we translated questions using an interpreter (most subcontractors have a "gatekeeper" who translates for the rest of the group). During the survey sessions which were administered in tea and smoking breaks on site, respondents were also permitted to openly discuss the questions which provided further insights into the issues being investigated.

Participation in the survey was entirely voluntary and a useable sample of 1155 questionnaires were collected (See Table 1 for sample structure).

The second stage survey aimed to explore supervisors' perceptions of cultural diversity on construction sites and to explore the strategies they used to manage diversity. It was distributed on sixteen construction sites and administered by hand during weekly subcontractors meetings where all managers, supervisors, foremen and engineers could be found at the same time. Participation in the survey was entirely voluntary a total of 204 questionnaires were collected (See Table 2 for sample structure).

\begin{tabular}{|c|c|c|}
\hline & & per cent $(\%)$ \\
\hline \multirow[t]{2}{*}{ Gender } & Male & 98 \\
\hline & Female & 2 \\
\hline \multirow[t]{3}{*}{ Age } & $18-34$ & 43 \\
\hline & $35-54$ & 47 \\
\hline & $55-64$ & 10 \\
\hline \multirow{6}{*}{$\begin{array}{l}\text { Educational } \\
\text { background }\end{array}$} & Technical or trade certificate & 40 \\
\hline & School certificate (Year 10) & 5 \\
\hline & $\begin{array}{l}\text { Higher secondary school } \\
\text { HSC/VCE }\end{array}$ & 9 \\
\hline & College certificate or diploma & 16 \\
\hline & Undergraduate degree & 23 \\
\hline & Postgraduate degree & 7 \\
\hline
\end{tabular}

Table 2 Respondent demographics, Supervisors' survey, Sydney construction sites, 2009

The third stage was a desk-top study of "best practices" in managing cultural diversity within the workplace. The desk-top study consisted of a review of a large number of online and published sources including specialised diversity reports, journal papers, books, company annual reports, company websites and press releases. In total, 156 companies were investigated across 15 industry sectors including hospitality, apparel, pharmaceuticals, entertainment media, information technology, internet services and retailing, megabanks, construction and engineering, health care, aviation, petroleum refining, and fast moving consumer goods. These companies were sourced from lists of the largest and most successful companies around the world:

- Engineering News Record's Top 400 Contractor List 2009;

- Fortune Magazine's World's Most Admired Company List for 2010 (People Management; and Management Quality) ; 
- Fortune Magazine's 100 Best Companies to Work For 2009; and

- Human Rights Campaign Foundation's Corporate Equality Index 2009.

A number of companies profiled were also acknowledged in the field as leaders in diversity management and some have won awards and accolades for their commitment and innovative solutions to managing cultural diversity and have been featured on award winning lists such as:

- Diversity Inc.'s Top 50 Companies List 2010;

- Diversity Inc.'s Top 10 Companies for Supplier Diversity List 2010; and

- Reader's Choice Best Diversity Companies 2009

\title{
Findings
}

The stage one survey of construction workers found that the majority of the respondents (85 per cent) interact with other ethnic groups during social situations and work-based activities suggesting that there is a good deal of cross-cultural interaction on construction sites. Half of the respondents indicated that most of their friends at work belonged to their own ethnic group and almost 31 per cent of respondents reported that they did not make an effort to talk with workers of different ethnic backgrounds. The majority of the respondents (76 per cent) believed "their own ethnic group understood them better" and 45 per cent of respondents reported that members of their own ethnic group needed to stick together to 'survive'. Our findings suggested that ethnic groupings can have both negative and positive functions. On the one hand, such ethnic groupings play a role in perpetuating the boundaries between different groups; potentially exacerbating a lack of cross-cultural understanding on construction sites. On the other hand, ethnic groupings (or in-group favouritism) have some positive functions such as maintaining positive bonds among group members, group support and providing safe-havens in conflict situations. For example, 45 per cent of respondents reported that members of their own ethnic group need to stick together to "survive" on construction sites. This is supported by the following statement made by a worker, which is typical of many made:

\begin{abstract}
Greeks stick together definitely... [Points out his Greek friend and says] For example, we don't talk too much, we're not close friends. But if something happens on the site or something that concerns all of us, then we stick together, definitely. We support each other (Site diary).
\end{abstract}

Maintaining in-group identification as a response to a threat is the strongest among respondents from Asian background. Almost 76 per cent of Asian respondents thought that they needed to stick together to survive on construction sites. These views suggest that threats to one's own ethnic group (or identity) provide stronger in-group identification. In this regard one may argue that in-group identification as a response to a threat is strongest among the members of major out-groups. The major out-groups on sites were perceived to be Australian-Lebanese, Asian-Australians, and those from the former Yugoslavia (mostly Australian-Serbians and Croatians). Having said this, the vast majority of workers were comfortable with cultural diversity and thought that it worked well. A vast majority of respondents (88 per cent) were of the view that cultural diversity is good for society and the construction industry. The majority of respondents are comfortable with working with people of different ethnic groups (88 per cent) and 77 per cent thought that different ethnic groups worked well on construction sites. A considerable percentage of respondents (32 per cent) thought that different ethnic groups should stay away from each other, thus implying that support for cultural diversity is not consistent and depends on the nature of the relationship 
between workers. There was a wide-spread belief that lack of interaction between certain groups is normal in the construction work environment. Despite this negative picture, 64 per cent of the respondents indicated that they would like to see more opportunities to mix with people from other ethnic groups while at work. So the picture which emerged was of high levels of cross-cultural interaction, and a general desire for more opportunities for meaningful cross-cultural contacts. At the same time, there is a comfort and confidence with in-group affiliation and association which indicates a co-existent politics of difference and a politics of identity, for which most workers can see merit in each.

Communication problems caused by language barriers were one of the major challenges affecting work and social relations between different ethnic groups on sites. Communication problems caused by language barriers are one of the major challenges affecting work and social relations between different ethnic groups on construction sites. A large number of respondents made comments about the low English proficiency of some groups (particularly Asian-Australian workers). The association of certain trades with certain ethnic groups (Italians in concreting, Koreans in tiling, Chinese in plaster boarding etc) deepens the complexity of language problems. Since each ethnic group tends to specialise in a particular trade, the workers of each trade tend to use their first language (if other than English) at the workplace. The intensity of communication problems becomes more challenging when workers of different subcontractors have to work together. One worker mentioned that different ethnic groups do not work well on site:

"due to language barriers and people not wanting to mix e.g all companies, subbies are made up of one ethnic group" (Comments in questionnaires).

The safety implications of language barriers were also raised by many workers.

Cultural diversity is a good thing for construction sites, yes but need to speak and understand English for safety aspects (Comments in questionnaires).

People should be able to read English when working on sites to read safety notices (Comments in questionnaires).

Cultural diversity is not a good thing "no, not when safety is compromised cause they are unable to understand, comprehend or speak English (Comments in questionnaires).

The majority (71 per cent) of respondents believed that there is equality of opportunity in the construction industry. However, 29 per cent of respondents reported differential treatment of ethnic groups. Derogative name calling was identified as one of the common experiences of workers with 32 per cent of respondents indicating that they have been called names or insulted because of their ethnic background. Offensive graffiti and joke telling were the most common forms of racial prejudice on construction sites.

The stage two survey of managers found that the majority of respondents believed that responsibility for managing ethnic diversity belonged to site managers, supervisors and project managers. Safety and equal opportunities policies were perceived to have more importance and be more widely implemented within the industry than affirmative action, Aboriginal employment and managing ethnic diversity policies. There was also a low level of awareness about ethnic diversity policies. 57 per cent of managers reported that they did not receive any training that aimed to reduce stereotyping and ways of managing ethnic diversity 
effectively. 54 per cent of the managers reported that they embraced a personal ethnic diversity management strategy to compensate for the lack of centralised policy. The other 46 per cent ignore the issue and rely on others to manage it for them. Indeed, most managers saw ethnic diversity strategies and affirmative action plans as discriminatory and unfair since such strategies may favour some groups over others. Managers of subcontractors were more actively involved in developing their own strategies than managers of main contractors. 13 per cent of the managers who did not have a personal strategy reported that having a strategy to manage ethnic diversity was not a priority. Organizing social events (such as barbeques and drinks in the pub) were listed as the most common form of ethnic diversity management strategy followed by multilingual induction processes. However, such events are recognised as inappropriate for some cultural groups and there was little imagination in managing this issue, probably because it was seen as such a low priority. A comparison of managers' and operatives' surveys suggests that operatives were slightly but not significantly less supportive of ethnic diversity (87 per cent), perhaps because they are directly exposed to its consequences. However, the overall level of support for diversity was very high in both groups. Significantly, around 23 per cent of managers thought that it would be better if different ethnic groups were separated. The majority of managers and operatives believed that there were sufficient opportunities for operatives to interact with workers from different ethnic backgrounds. More than half of the managers did not identify any problems with ethnic diversity and did not see any need to manage it proactively. In summary, the cultural diversity of the industry appears to be taken for granted by project managers and it appears as if the problems associated with it are accepted as an inevitable part of daily life on construction sites.

The stage three desk-top study findings highlight the types of management strategies which could be employed by construction firms to address the above problems. These are critically appraised below from a social identity perspective and are categorised under four main headings: leadership and commitment; education; networking and; subcontractor and supplier diversity programs.

\section{Leadership and Commitment \\ Creating a diversity portfolio}

The appointment of a senior executive to champion and lead diversity initiatives is a common strategy used by the firms we reviewed. Senior management positions such as 'Chief Diversity Officer' or 'Global Chief of Diversity' are common with direct reporting responsibilities to the CEO to ensure diversity remains a "strategic" priority. While on the surface this approach would seem positive in creating a focus on the management of cultural diversity which our stage one and two results show is missing from the construction industry, this approach can also be criticised from a social identity perspective. In particular, the "separating out" diversity as an issue could be counter-productive by potentially reinforce workplace differences as a management "problem". From a social identity perspective, a more positive approach would be to "normalise" diversity and multiculturalism by making it an integral part of "everyone's" job rather than separated which everyone is expected to give attention to on a day-to-day basis.

\section{Measuring and reporting diversity performance}

Companies committed to diversity initiatives often establish measurable key performance indicators (KPIs) that enable them to monitor and report the return on investment and the effectiveness of diversity initiatives implemented. Diversity KPIs may include: number of clients from different minority groups; number of senior managers from minority groups; levels of acceptance and satisfaction among employees; grievances and complaints; workplace conflict and disputes; retention; recruitment; community and public image etc. These companies also actively participate in specialist rankings as a way to build brand recognition in the marketplace. Once again, this might seem a useful way to "measure" and thereby track and adjust diversity performance and address the "taken for granted" nature of

Loosemore, $\mathrm{M}$ et al. (2012) 'Management strategies to harness cultural diversity on Australian construction sites - a social identity perspective', Australasian Journal of Construction Economics and Building, 12 (1) 1-11 
the problem discovered in stages one and two of our research. However, the effectiveness of this strategy from a social identity perspective lies in whether the metrics reinforce or erode perceptions of difference. For example, by highlighting a certain group as one which needs a proportion to be represented as certain levels is to accentuate difference. In social identity terms, it would be better to measure these indicators for every cultural group.

\section{Education}

\section{Diversity training}

Leading companies integrate diversity training into their overall training program and this would appear to be an effective strategy for addressing the general ignorance of cultural diversity management strategies which we discovered in our stage one and two research. Typically, these courses cover a wide range of topics such as the rights and obligations of employees, anti-discrimination legislation and strategies for dealing with workplace discrimination. Other companies emphasise more practical day-to-day managerial approaches for dealing with diversity, such as how to overcome negative behaviours, attitudes and stereotypes. Some organisations utilise more centralised and specialised methods of disseminating information on cultural diversity. For example, one company uses a 'Cultural Dictionary' to provide cultural insights and quick access to a variety of information about different groups including language, religion, general attitudes, greetings, gestures, eating habits, lifestyle and family etc. From a social identity perspective, education (for all not just for one group) is a positive way to erode difference in the workplace and encourage a sense of collective multiculturalism.

\section{Language proficiency}

The ability to communicate in a language other than English is a quality that companies increasingly value as a resource to help bridge cultural divides. For example, some companies proactively encourage native speakers from culturally and linguistically diverse backgrounds (CALD) to undertake a language competency test so that they can become qualified interpreters. Other companies provide language courses to encourage multilingualism. Certainly, given the language problems uncovered in stage one and two of this research, this would appear to be an important strategy for the construction sector to consider. However, from a social identity perspective, these initiatives are positive as long as they are not imposing a dominant language on a minority group. Social identity theory would advocate "meeting in the middle" by encouraging all groups to learn each other's language rather than expecting one language to be the "nominated and accepted" language that everyone speaks.

\section{Cultural integration opportunities}

Our stage one and stage two results showed that people working on construction sites desire more opportunities to interact with people from other cultural groups. Our stage three research showed that leading companies employ numerous strategies to bring different cultural groups together. For example, some companies organise a diversity week where members of different cultural groups are invited informally to share their cultural food, drinks, cooking lessons and cultural knowledge. Other companies employ a far more structured approach with a diversity calendar with a detailed listing of cultural events. Once again, a social identity perspective would see this as "setting aside" special resources and events outside the work context. According to social identity theory, if such events are to have any effect, they should be played out in a work context and not be separated out. They should happen naturally and spontaneously all the time and they should not be targeted at specific groups.

\section{Cultural holidays}

Different cultural and ethnic groups celebrate events and holidays that have specific cultural value and significance to them. In acknowledging this, some companies implement a 'Floating Cultural Holiday Policy' that gives employees the option of 'trading' official public 
holidays for a day that is of cultural significance to them. From a social identity perspective this strategy is negative in that it requires someone to "trade" their identity for another. A far better approach would be to make these holidays an additional entitlement on top of shared holidays that everyone receives.

\section{Role modelling}

Many companies believe that positive role modelling of successful and inspirational employees from minority groups can have a significant motivational impact within minority groups. For example, some companies have started role modelling successful ethnic minorities in senior positions. From their "stories", it is argued that other employees of similar ethnicity can learn important lessons about the challenges that they may experience in achieving and maintaining senior positions. However, from a social network perspective, role models simply highlight the fact that it is more difficult for someone from this group to progress through a company. In other words, this person is not "normal" and has a separate identity to the rest of the organisation. To be effective, role models should target roles not groups.

\section{Networking \\ Employee groups}

Employee groups are highly valued by some companies which often contribute resources and expertise to help them build capacity and which frequently consult them on areas relating to strategy, diversity policy and professional development. However, from a social identity perspective, the idea of creating a Chinese group to advise on Chinese strategy is an anathema. It is difficult to think of a management strategy that could be more delineating or divisive.

\section{Mentoring}

Mentoring programs are increasingly used to enable employees from minority backgrounds to access support, identify pathways and source knowledge they need to reach their full potential at work. Some programs match people from different backgrounds and provides training to mentors to help them manage this process, regularly monitoring mentor and mentee performance in achieving pre-determined diversity and inclusion goals. Other companies go one step further by implementing a "reverse mentoring" programme that pairs very senior and successful managers up with junior mentors of culturally diverse backgrounds. The program aims to provide very senior managers with a practical insight into diversity issues from an alternative viewpoint. From a social identity perspective this is excellent since it blurs and mixes the strata's of identity creating a collective corporate identity which is devoid of difference.

\section{Supplier or subcontractor diversity}

\section{Supplier or subcontractor guidelines and codes of practice}

To ensure a high standard of behaviour and integrity of the suppliers and subcontractors they use, many companies expect suppliers and subcontractors to adhere to rules and guidelines governing the way they operate their business, including codes of conduct and ethics and requirements for maintaining a culturally diverse workforce. From a social identity perspective, the problem with this approach is the underlying assumption that parent company policies and procedures are superior. Given the critical analysis of the above strategies, this clearly cannot be assumed.

\section{Strategic allocation of contracts}

A large number of companies strategically allocate a proportion of contracts to minorityowned businesses. For example, some companies allocate between $12 \%$ to $15 \%$ of total annual procurement dollars to minority-owned businesses in the belief that it contributes towards the development of historically under-represented entrepreneurs. Other companies

Loosemore, $\mathrm{M}$ et al. (2012) 'Management strategies to harness cultural diversity on Australian construction sites - a social identity perspective', Australasian Journal of Construction Economics and Building, 12 (1) 1-11 
sponsor procurement fairs, to inform potential minority-owned businesses about the opportunities of working on their projects and to introduce them to prime contractors. And several companies have online supplier registry to nurture partnerships with qualified diverse suppliers and subcontractors. From the perspective of social identity theory, this is equivalent to an affirmative action program which once again reinforces difference by separating out particular groups for special attention. A more effective approach would be to support companies so that they can compete equally.

\section{Conclusion}

The aim of this paper was to use social identity theory to explore the attitudes that underpin cultural diversity in the Australian construction industry, the management challenges that these pose and the range of strategies that can be employed to manage them effectively. While the research reported here has been undertaken in Australian construction industry, the findings are of relevance to construction industries elsewhere given the workforce demographic and institutional similarities between them. Our findings indicate that construction workers take the cultural diversity of the industry for granted, are optimistic and positive about diversity and have cross-ethnic experiences which generally leave them happy for further contact. Yet, they exist in an environment of ambient racism and retain a set of assumptions regarding the desirability of ethnic uniformity (sameness) over diversity. While there was some acceptance that management should take responsibility for ethnic diversity management, it was not seen as a priority and for some there was no perceived problem to manage. The latter views are inconsistent with the findings on the perceptions of uneven opportunities and of experiences of everyday racism. They also conflict with the findings of cross cultural social identity research which indicates that the best way to manage diversity is to diffuse responsibility throughout the workforce rather than assume it is the responsibility of one group (managers). Our research also shows that most of the extant strategies for managing diversity are ad-hoc and informal, and principally include social functions arranged by workers or unions. This is hardly surprising given that there is an absence of formal training on diversity management for both workers and managers. Not only is diversity being poorly managed, exposing the industry to the costs of poor inter-ethnic relations, but the wider social benefits from improving attitudes among this section of society are not being reaped. No construction or engineering companies reside in the recognised global leaders of best practice which in terms of the attitudes discovered towards diversity is not surprising. In stark contrast to the finely detailed information we found in the companies we reviewed, the limited number of initiatives we could find in the construction sector were typically poorly documented and ad hoc and there was little evidence of them fitting into strategic, detailed and fully integrated diversity programs which are systematically measured and reported in terms of their success and return of investment. However, while more research is needed to explore, analyse and test the effectiveness of the full variety of diversity strategies higlighted in this paper, our critical analysis using social identity theory suggest that firms should be wary of many of the so called best practice strategies which are promoted in the literature. We have shown that many of these could reinforce rather than eliminate cultural difference and can actively undermine attempts to build a cooperative workplace culture where different cultural groups can work in the harmony that most of them appear to desire. In conclusion, we would argue that any research into effective workplace strategies to manage diversity in the construction and engineering sectors be informed by relevant social psychological research and not be uncritically adopted without any thought to their application and unintended consequences. We would also point out that further research needs to be undertaken into differences in attitude towards cultural diversity between different ethnic groups. One of the limitations of this research was that attitudes could not be analyzed and compared across these groups. Such research would enable more targeted strategies than the generic strategies highlighted in this paper.

Loosemore, $\mathrm{M}$ et al. (2012) 'Management strategies to harness cultural diversity on Australian construction sites - a social identity perspective', Australasian Journal of Construction Economics and Building, 12 (1) 1-11 


\section{References}

Brewer, M. B. (1997) 'The social psychology of intergroup relations: can research inform practice?', Journal of social issues, 53 (1) 197-211

Brewer, M. B. (2009), 'The importance of being we: Human nature and intergroup relations', American Psychologist, 62, 728-738

Cox, T.H. and Blake, S. (1991) 'Managing cultural diversity: implications for organizational competitiveness', Academy of Management Executive, 5 (3), 45-56

Dainty, A., Green, S., Bagilhole, B. (eds.) (2007) People and Culture in Construction: A Reader, Taylor \& Francis, Oxon

De Cieri, H. and Kramar, R. (2003) Human Resource Management in Australia: Strategy, People, Performance, McGraw Hill, Sydney

Dunn, Kevin M., Forrest J., Pe-Pua, R., Hynes M. and Maeder-Han, K. (2009) 'Cities of race hatred? The spheres of racism and anti-racism in contemporary Australian cities', Cosmopolitan Civil Societies: An Interdisciplinary Journal, 1 (1), 1-14

Gale, A. W. and Davidson, M. J. (eds.) (2006) Managing Diversity and Equality in Construction Initiatives and practice, Taylor \&Francis, Oxon

Hay, C. (1996) Managing cultural diversity: Opportunities for enhancing the competitive advantage of Australian Business, AGS, Canberra

Loosemore, M. and Lee, P. (2003) 'An investigation into communication problems with ethnic minorities in the construction industry', International Journal of project Management, 20 (3), $517-524$

Loosemore , M., Dainty, A. and Lingard, H. (2003) Human Resource Management in the Construction Industry: Strategic and Operational Approaches, Taylor and Francis, London, UK

Loosemore, M. and Andonakis, N.(2006) 'Subcontractor barriers to effective OHS compliance in the Australian Construction Industry', in Fang D. P., Choudry, R.M. and Hinze, J. W.(eds.), Global Unity for safety and health in construction proceedings of the CIB W99 International conference, Tsinghua University, Beijing, 61-68

Loosemore, M., Phua, F., Dunn, K. and Ozguc, U. (2010) Key findings of survey with site operatives: Managing Cultural Diversity on Australian Construction Sites, First report of Australian Research Council Grant, UNSW, Sydney, Australia

Loosemore, M., Phua, F., Dunn, K. and Ozguc, U. (2010), 'Managing cultural diversity in Australia construction sites', Construction Management and Economics, 28 (2), 177-188

Ofori, G. (1994) Foreign construction workers in Singapore, International labour Organization, International labour Office, Geneva

Steele, A. and Sodhi, D. (2006) Race, ethnic minorities and construction industry in Gale, A.W. and Davidson, M.J.(eds.), Managing Diversity and Equality in construction: Initiatives and practice, Taylor \& Francis, Oxon

Tajfel, H. (1970) Experiments in intergroup discrimination, Scientific American, 223 (2), $96-$ 102

Van Oudenhoven, J. P., Groenewoud, J. T. and Hewstone, M. (1996) 'Cooperation, ethnic salience and generalization of interethnic attitudes', European Journal of Social Psychology, 26, 649-661 